\title{
Research on Building Electronic Port Information Platform of Airport Economic Zone
}

\author{
Yang Changhui*
}

School of Business, Zhengzou University, Zhengzhou, Henan, 450001, P.R. China

\begin{abstract}
Information technology has been widely used in the enterprise in airport economic zone and the daily management of government. The use of information technology construction of airport economic zone electronic port information platform helps to promote financial electronic, trade electronic, customs clearance electronic and tax electronic development and integration. This paper firstly analyzes the main business requirements and application module of the electronic port information platform, and then puts forward the overall structure and network topology structure of the information platform and analyzes the main application system of the information platform. The application of airport economic zone electronic port information platform helps to realize the interaction among airport economic zone information flow, capital flow and logistics, realize the enterprise online customs clearance, improve customs clearance speed, reduce trade cost and improve enterprise competitiveness.
\end{abstract}

Keywords: Airport economic zone, application system, electronic port information platform, network topology structure, system structure.

\section{INTRODUCTION}

At present, under the trend of economic globalization and regional economic integration, the world science and technology changes with each passing day and the competition in overall national strength is becoming increasingly fierce. Using modern information technology to improve customs clearance speed, reduce trade cost and improve enterprise international competitiveness has become an effective way to realize the trade facilitation. Airport economic zone electronic port information platform involves finance, trade, customs, taxation, insurance, inspection and quarantine, transportation and maritime industries. The construction of airport economic zone electronic port platform will promote the development of financial electronic, trade electronic, customs clearance electronic and tax electronic, so as to improve administrative efficiency and reduce trade costs, enhance the competitiveness of enterprises and promote the the interaction among airport economic zone information flow, capital flow and logistics, realize enterprise online customs clearance and online work, greatly facilitate the business and reduce costs.

\section{ELECTRONIC PORT INFORMATION PLATFORM OVERVIEW OF AIRPORT ECONOMIC ZONE}

Airport economic zone electronic port information platform is using the modern information technology, with the aid of national telecommunication public network and all kinds of import and export of electronic enterprise data are centralized to the public data center, the state administrative department of functions can be across departments, crossindustry networking data verification, enterprises can deal with all kinds of import and export business on the Internet [1-3].

The construction of airport economic zone electronic port information platform is based on network platform and take the airport economic zone electronic port portal website as the carrier [4]. Through the portal website, it integrates electronic port online clearance, online logistics, port information, personalized service and unified security authentication five plates as a whole, realizing data sharing and networking application, networking verification and networking operation [5]. And establish the land, waterways, railways, civil aviation, port and other port logistics information system, provide government affairs public, information consultation and related electronic commerce services, realize the online "one-stop", "a table type", "a net type" service, enhance the working efficiency of the government, law enforcement and various enterprises, service for airport economic zone economic development.

The construction of airport economic zone electronic port information platform takes the service for the tenet and promoting for the purpose and promote development through cooperation.

For the tenet of service: The fundamental starting point of electronic port information platform construction is for administrative law enforcement departments to strengthen effective regulation and improve administrative efficiency services, for the majority of enterprises in the region to improve the clearance speed, lower trading costs and improve the service of international competitiveness.

For the purpose of promoting: Build the unified information platform of large customs clearance, large logistics and 


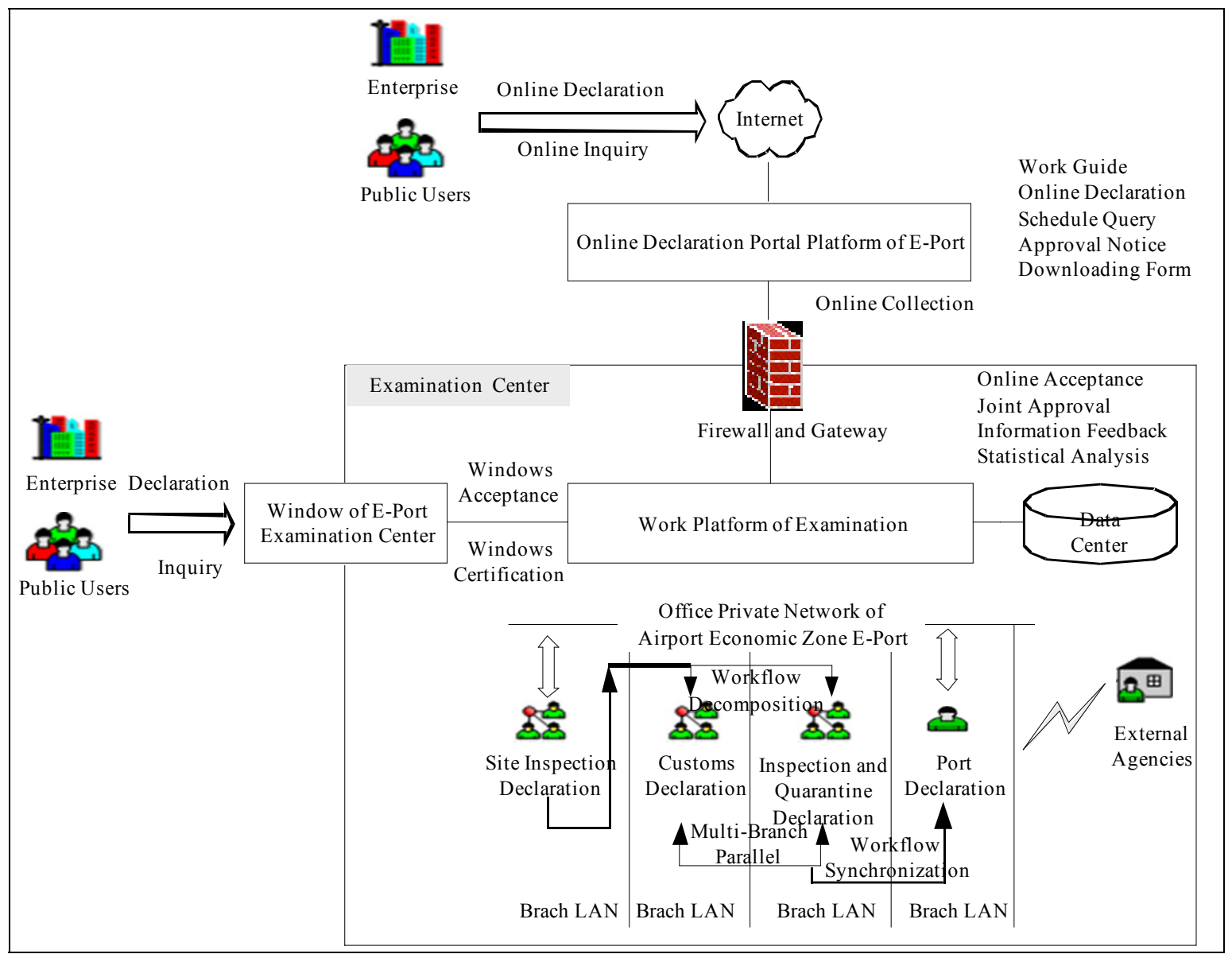

Fig. (1). Online examination and approval flow figure.

large foreign trade; achieve port management and services information sharing; enhance the international competitiveness of enterprises, ports and even the country and promote the healthy development of an open economy.

Promoting development through cooperation: Electronic port information platform construction must closely rely on the strong leadership of the government and the close collaboration of the relevant departments. Play well and protect well the enthusiasm of each respect, mutual benefit, seeking common ground while putting aside differences and common development.

\section{ANALYSIS MAIN BUSINESS OF ELECTRONIC PORT INFORMATION PLATFORM}

\subsection{Online Examination and Approval}

Online examination and approval system is an important part of electronic port system. The implementation of the online examination and approval system helps to improve the government efficiency, simplify the process and promote the government's work to the transformation of a serviceoriented government. Online examination and approval system through the advanced platform technology and design architecture, tightly integrated office automation system, established the online channel between the government and the enterprises and the public, realize the online consultation, inquery, application, examination and approval, complaints, supervision and other business functions, become a real web portal for online office and work, closer the distance between the enterprises, residents and government departments, improve efficiency and strengthen the government image [6, 7].

Online examination and approval system needs to provide users with a unified portal entrance. The users through the Internet portal entrance log in, choose the relevant examination and approval matters and fill in relevant information. The data will be automatically transferred to the scheduling platform. Concrete tasks through data sharing and exchanging platform are given to relevant departments. The state and the results that the relevant departments deal with will feedback by data sharing and exchanging platform to business support platform, and then inform the users through the portal website by business support platform. One-stop online approval process is shown in Fig. (1).

\subsection{The Main Application Module of Electronic Port Information Platform}

Electronic port portal website integrates electronic port online clearance, online logistics, port information, personalized service and unified security authentication five plates as a whole, as shown in Fig. (2). Realizing data sharing and networking application, networking verification and networking operation. On the platform at the same time set up land, waterways, railways, civil aviation, port and other port logistics information system, and can provide government affairs public, information consultation and related e- 


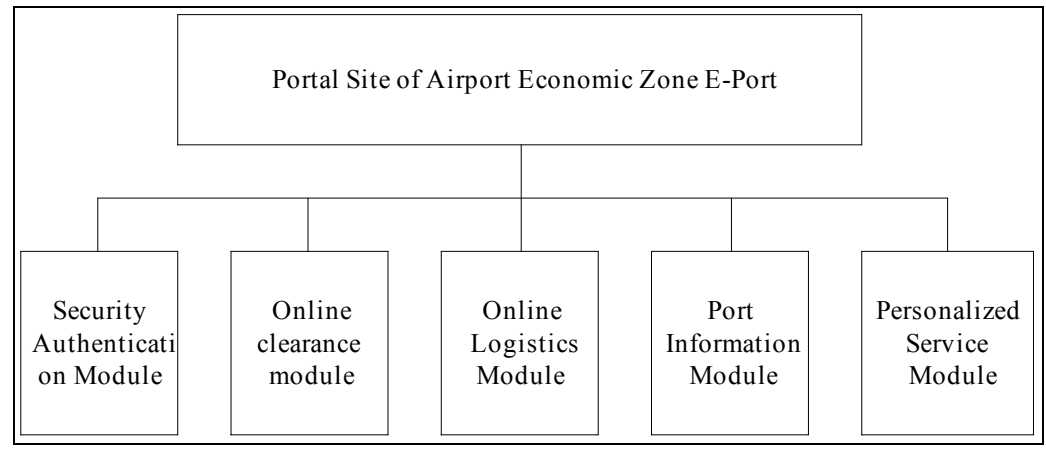

Fig. (2). Electronic port portal website application module structure figure.

commerce services, service for airport economic zone economic development [8].

Electronic port online customs clearance module: Uniformly packagting the customs clearance service system of China port electronic law enforcement system and the related law enforcement department on electronic port information platform, so that the airport economic zone import and export enterprises, logistics companies and other users through this platform can conduct various customs clearance business operation. And then realize the online "one-stop", "a table type", "a net type" service, improve the work efficiency of the government, law enforcement, and various enterprises [9]. It mainly includes two application projects: China electronic port electronic law enforcement application projects and local law enforcement law enforcement application project.

Electronic port online logistics module: According to the needs of airport economic zone developing modern logistics industry, and combined with local actual situation, put forward demand by enterprise customers, in electronic port information platform develope with regional characteristics in the service of modern logistics application project. Take this opportunity to improve the informationization level and market competitiveness of airport economic zone logistics industry and promote the development of airport economic zone logistics industry.

Port information module: Port information module main contents include: Port dynamics, policies and regulations, business training, customs clearance guide, business information search, online clearance hotline, online complaints hotline.

Personalized service module: In order to better provide quality services for the member and according to the development requirements of the business and the actual needs of enterprise, Guangxi electronic port platform will provide more expansion and extension member service, to make enterprises to be more convenient and more real-time understanding of the relevant information to achieve the goal of both sides profit. Personalized service module mainly includes: SMS services, e-mail services, online payment services, mailing services, agency services and other ways to expand services.

Unified security authentication module of electronic port information platform: The ultimate goal of electronic port information platform construction is through the China EPort "safety \& exchange" platform to realize "one point access, once certification". But at present, due to various rea- sons, "safety \& exchange" platform can only play the channel effect, it cannot achieve the function of safety certification. Therefore, to ensure the safe operation of airport economic zone electronic port information platform, it must develop an independent security certification platform in the basis of China E-Port "safe \& exchange" platform. Through this platform, the user through a safety certification can use local application projects of airport economic zone electronic port information platform. Functions of unified security authentication platform construction are: one is for the future to realize electronic port "one point access, once certification" lay the foundation; the second is to provide unified security authentication interface for application development and reduce the application project development costs.

\section{SYSTEM STRUCTURE AND NETWORK STRUC- TURE OF INFORMATION PLATFORM}

\subsection{System Structure of Information Platform}

Electronic port platform overall architecture can be divided into six layers, the first layer is the service performance layer, including network office job portals and electronic port networks outside the portal. The second layer is the business layer, including e-mail system for providing services, coordination office system, public information service system, the CA certification center, the customs personnel management system, online customs clearance system, logistics management system, digital monitoring system, exit vehicles for the record of examination and approval system, etc [10]. The third layer is the application supporting platform. The fourth layer is the data exchange platform. The fifth layer is the system software platform. The sixth layer is network and hardware platform. As shown in Fig. (3).

Intranet users achieve coordination office. Individuals, businesses and other users can access to the unified portal through the Internet, and through this portal seamless access to the various application systems. And the user can customize their portal according to their own habits and interests.

According to the different business logic and needs of use, in accordance with the unified regulations of foundation platform and data exchange storage requirements, the system can be constructed and extended. On the basis of the unified regulations management ensure the scalability of system function.

As part of the foundation platform, provide the support of underlying public function module. Avoid repeated construc- 


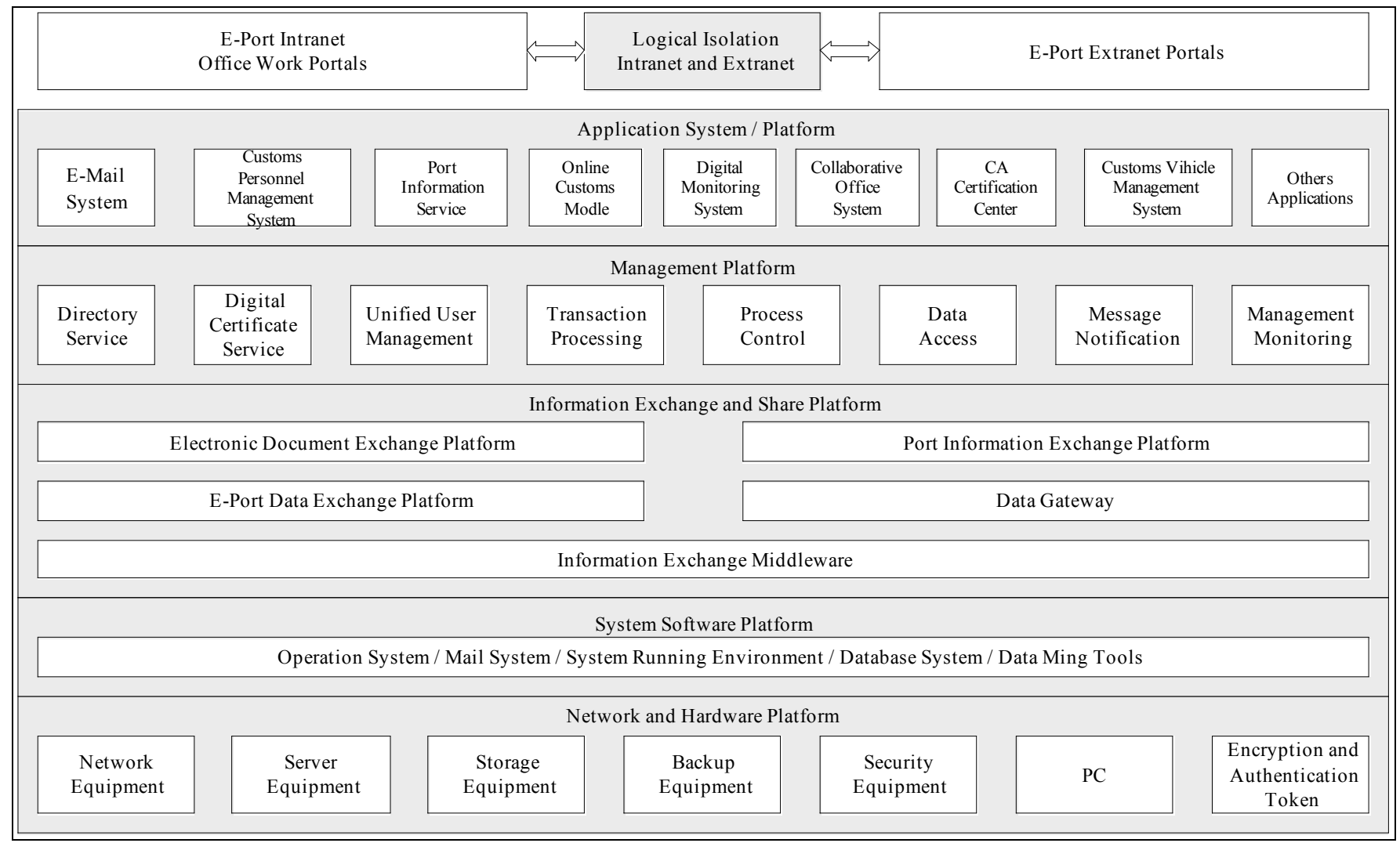

Fig. (3). System structure of electronic port information platform.

tion maintenance, at the same time, determine the corresponding unified specification and standard, making business collaboration and data integration possible.

As part of the foundation platform, exchange platform bears the function of the information data exchange routing among different systems. Different system can be information data exchanging through the platform, and also in the process of business process keep the data in different systems.

Establish a unified network system. According to the system scale to establish the corresponding center machine room, server configuration, storage equipment and security equipment, etc.

\subsection{Network Structure of Information Platform}

(1) The network system design principles

Network system is the important foundation of this system efficient and reliable operation, so set a reasonable and necessary network design principle is the guarantee of success of network design $[11,12]$. The network system design of this system are on the basis of the following design principles:

$\diamond \quad$ The balance of the system safety and efficiency;

$\diamond$ System topology structure ensures the high-efficiency and safe operation of three layers framework of the system;

$\diamond$ Important equipment, link backup, avoid the failure of single point;

$\diamond \quad$ Strive for simple network structure, in order to reduce system overhead and the point of failure; $\diamond$ Try to reduce the system operation and maintenance cost;

$\diamond \quad$ Ensure appropriate equipment capacity redundancy.

(2) Topology structure of the network platform

According to the above requirements, electronic port foundation platform mainly includes the core part of electronic port network platform, private network of electronic port and related units and port field access three parts. Through the "security and exchange system", electronic port private network and the core part of electronic port network platform are connected to the China electronic port platform, achieving the function of the longitudinal and transverse data security exchange [13]. Network topology structure is shown in Fig. (4).

\section{ANALYSIS OF MAIN APPLICATION SYSTEM OF INFORMATION PLATFORM}

\subsection{The Entry and Exit Vehicle Approval and Filing Sys- tem}

The main modules of the entry and exit vehicle approval and filing system include: operational qualification application module, the examination and approval administration module, approval for the record management module and information inquiry module [14].

The main business process of the entry and exit vehicle approval and filing system is as follows:

$\diamond \quad$ Transport enterprises to be operated in international traffic $\log$ in Guangxi electronic port platform and put for- 


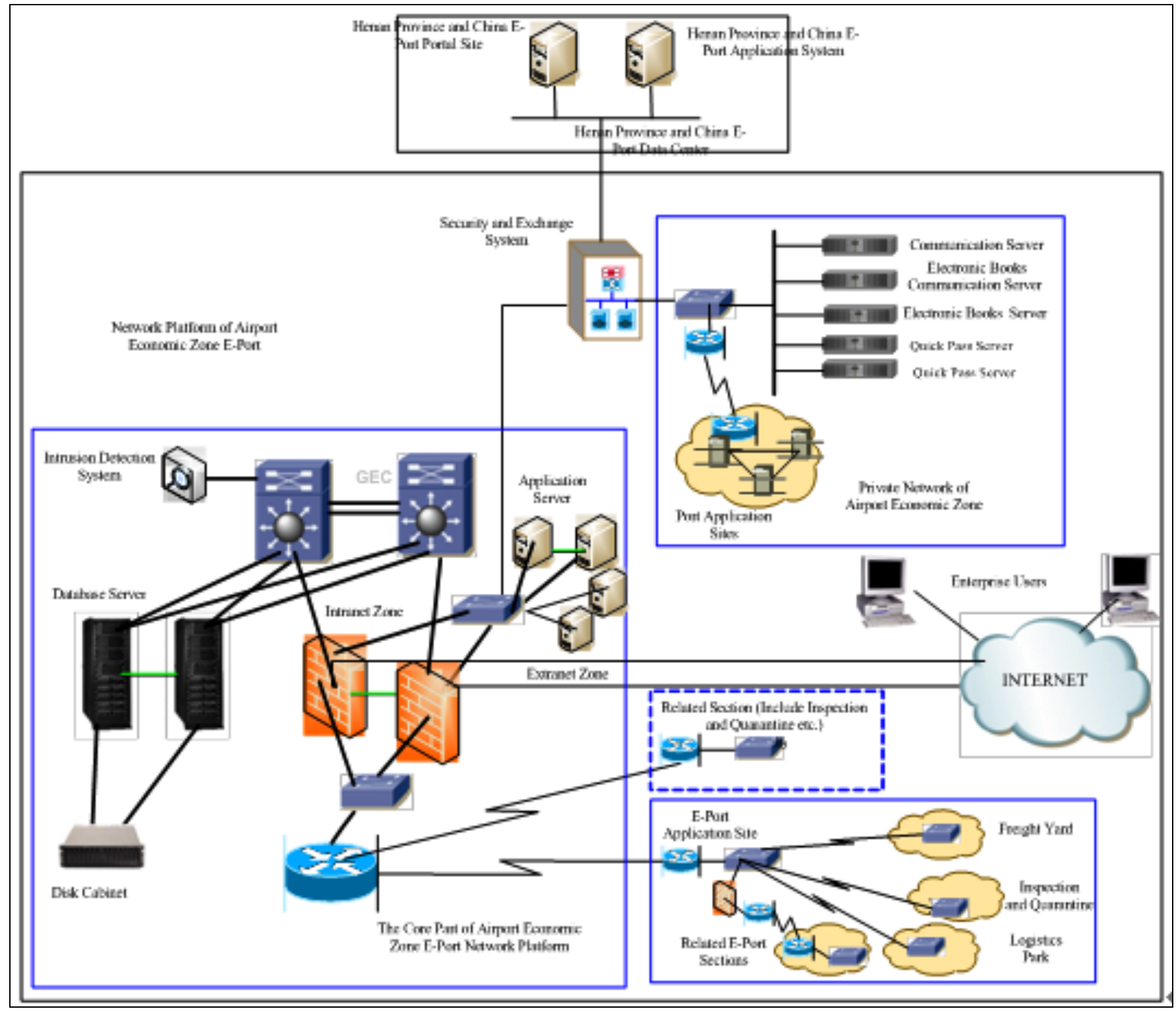

Fig. (4). Network topology structure of electronic port information platform.

ward the operating qualification application to the traffic administrative department (application information include enterprise and vehicle information).

$\diamond$ Electronic port platform handover the application information to the traffic administrative department.

$\diamond \quad$ The traffic administrative department by regulation examine and approve transport enterprises application. Give the international transport qualification to the transport enterprises meet the requirement and put on records of the vehicle of the enterprise. The result of examination and approval through the Guangxi electronic port platform feedback to the applicant.

$\diamond$ Electronic port platform will inform the customs of the vehicle registration information that the traffic administrative department approved. After transportation enterprises received approval results from the traffic administrative department can they carry out the international shipping business.

\subsection{Logistics Management System}

Logistics management system mainly includes: road transport management module, inbound and outbound management module, inspection and quarantine module, customs formalities module, approve release module and query module.

The main functions of the logistics management system include:

Road transport management module: record the transportation owners, basic information of users and the basic message of tools, license issue management and advantageous for the query.

Inbound and outbound management module: after the frontier inspection of inbound and outbound means of transport and related personnel, record the results of the inspection, issue license and record the related results in order to query. 
Inspection and quarantine module: after the inspection and quarantine disinfection of inbound and outbound means of transport and related personnel, record the results, issue related license and record in order to query.

Customs formalities module: prepare relevant documents, go through customs and record results in order to query.

Approve release module: check the related documents, the approval and record for the record in order to query.

Query module: make it easy for users to query the requested information.

\subsection{Inbound and Outbound Personnel Management Sys- tem}

Inbound and outbound personnel management system mainly include: inbound and outbound means of transport and staff forecast preview management, inbound and outbound personnel forecast preview management, inspection and quarantine management, customs inspection management and approval of release management, etc.

Inbound and outbound means of transport and staff forecast preview management: manage and record means of transport of inbound and outbound and the basic information of the driver, issue entry and exit permit in order to query.

Inbound and outbound personnel forecast preview management: manage and record the basic information of inbound and outbound passengers, issue entry and exit permit in order to query.

Inspection and quarantine management: carry on the inspection and quarantine to means of transport and drivers of inbound and outbound, as well as inbound and outbound passengers according to relevant laws and regulations, and record the results of inspection and quarantine in order to query.

Customs inspection management: carry on the customs check to means of transport and drivers of inbound and outbound, as well as inbound and outbound passengers according to relevant laws and regulations, and record the results in order to query.

Approval of release management: check the related information, and release after correct, record the relevant information in order to query.

\subsection{Digital Video Monitoring System}

Digital video monitoring system to realize the on-site monitoring of entry-exit personnel and vehicles of the business field within the scope of jurisdiction, can monitor center at the scene and master monitoring points situation in realtime, and at any time will reflect suspicious situation to the site personnel on duty to ensure the smooth progress in field work [15]. System is able to upload the video information and relevant data through the network to the friendship gate and realize remote monitoring function, making the remote user real-time monitor and manage the content of the monitoring, and record a video of all monitoring business outlets.

\section{CONCLUSION}

Airport economic zone directly or indirectly influences on the economy of surrounding areas, causing agglomeration effect and diffusion effect. Electronic port information platform by using modern information technology construction and implement the integration among financial electronic, trade electronic, customs clearance electronic, tax electronic can improve the administrative efficiency, reduce the trade cost, improve enterprise competitiveness, promote the interaction among airport economic zone information flow, capital flow and logistics, realize the online customs clearance and online work, greatly facilitate enterprises and reduce the cost. This paper analyzes the main business processes of airport economic zone electronic port information platform, and then discusses the overall structure of electronic port information platform, after that puts forward the network topology structure model of electronic port information platform and analyzes the main application system.

\section{ABOUT THE AUTHOR}

Yang Changhui, Graduated from Central South University, and now working at business school of Zhengzhou University, the main research directions include operation management, supply chain management and management information system.

\section{CONFLICT OF INTEREST}

The author confirms that this article content has no conflict of interest.

\section{ACKNOWLEDGEMENTS}

This paper was supported by NSFC (71272207, 71301150, U1404704), 10YJC630326 and 14YJC630126 (Humanity and Social Science Foundation of Ministry of Education).

\section{REFERENCES}

[1] Z. Yunfan, and X. Yabin, "Based on CTI technology call center design and realization", Liaoning Engineering Institute Journal, vol. 2, pp. 51-58, 2006.

[2] J. Bo, C. Ming, and G. Guanqing, "Distributional and central unifies call center”, Computer Application, vol. 7, pp. 46-51, 2002.

[3] C. Wenhua, H. Xiaoping, C. Kai, and B. Yingcai, "Based on VoIP technology virtual call center design and realization", Computer Application and Software, vol. 2, pp. 33-42, 2006.

[4] G. Jongbloed, and G. Koole, "Managing uncertainty in call centers using Poisson mixtures", Applied Stochastic Models in Business and Industry, vol. 17, pp. 307-318, 2001.

[5] L. Ji, K. Luo, and H. Tan, "Based on three structures disperser -like call center system", Computer Application, vol. 12, pp. 66-73, 2004.

[6] Yang Changhui, "Research on service call center construct of digital city management system", Journal of Information and Computational Science, vol. 8, no. 2, pp. 246-252, 2011.

[7] N. Prindezis, and C. T. Kiranoudis, "An internet-based logistics management system for enterprise chains", Journal of Food Engineering, vol. 70, no. 3, pp. 373-381, 2005.

[8] J. Santa, M.A. Zamora-Izquierdo, A.J. Jara, and A.F. GomezSkarmeta, "Telematic platform for integral management of agricultural/perishable goods in terrestrial logistics", Computers and Electronics in Agriculture, vol. 80, pp. 31-40, 2012.

[9] Y. Changhui, "Supplier selection mechanism of logistic enterprise based on multi-agent system", International Journal of Advancements in Computing Technology, vol. 4, no. 16, pp. 437-444, 2012.

[10] J. D. Nelson, and C. Mulley, "The impact of application of new technology on public transport service provision and the passenger experience: A focus on implement in Australia", Research In Transportation Economics, vol. 39, no. 1, pp. 300-308, 2013. 
[11] C. Lu, K. Tsai, J. Chen, and W. Lee, "Mitigating the bullwhio effect in the supply chain of semiconductor assembly and testing through an inter-business information platform", International Journal of Electronic Business Management, vol. 11, no. 3, pp. 202-211, 2013.

[12] C. Yang, and Kang Ju, "Research on business process and ebusiness platform design of barter trade", Information Technology Journal, vol. 12, no. 19, pp. 5315-5320, 2013.

[13] Z. Wu, and X. Mao, "Study on construction of information service platform for pharmaceutical enterprises based on virtual cloud envi- ronment", Journal of Chemical \& Pharmaceutical Research, vol. 6, no. 1, pp. 1004-1010, 2014.

[14] C. Yang, "Research on construction of Digital Intelligent City Management System", International Journal of Hybrid Information Technology, vol. 7, no. 5, pp. 285-294, 2014.

[15] C. Li, X. Zhang, and L. Li, "Research on comparative analysis of regional logistics information platform operation mode based on cloud computing", International Journal of Future Generation Communication \& Networking, vol. 7, no. 2, pp. 73-80, 2014.

Received: September 16, 2014

Revised: December 23, 2014

Accepted: December 31, 2014

(c) Yang Changhui; Licensee Bentham Open.

This is an open access article licensed under the terms of the Creative Commons Attribution Non-Commercial License (http://creativecommons.org/licenses/by-nc/3.0/) which permits unrestricted, non-commercial use, distribution and reproduction in any medium, provided the work is properly cited. 